\title{
Knowledge creation in IJVs: the mediating role of formal and informal communication
}

Book or Report Section

Accepted Version

Lee, J. M. and Pak, Y. S. (2016) Knowledge creation in IJVs: the mediating role of formal and informal communication. In: Academy of Management Proceedings. Academy of Management, pp. 1634-1639. doi: https://doi.org/10.5465/AMBPP.2016.242 Available at https://centaur.reading.ac.uk/72646/

It is advisable to refer to the publisher's version if you intend to cite from the work. See Guidance on citing.

Published version at: http://proceedings.aom.org/content/2016/1/16550.abstract?sid=84468078-85b9-415f-a0db028973859418

To link to this article DOI: http://dx.doi.org/10.5465/AMBPP.2016.242

Publisher: Academy of Management

All outputs in CentAUR are protected by Intellectual Property Rights law, including copyright law. Copyright and IPR is retained by the creators or other copyright holders. Terms and conditions for use of this material are defined in the End User Agreement.

www.reading.ac.uk/centaur

\section{CentAUR}


Central Archive at the University of Reading

Reading's research outputs online 


\title{
KNOWLEDGE CREATION IN IJVS: THE MEDIATING ROLE OF FORMAL AND INFORMAL COMMUNICATION
}

\author{
YONG SUHK PAK \\ School of Business, Yonsei University \\ 50 Yonsei-ro, Seodaemun-gu, Seoul, 120-749, Korea \\ JONG MIN LEE \\ Henley Business School, University of Reading
}

\section{INTRODUCTION}

Over the last two decades, knowledge management has gradually emerged as a prime topic in the international joint venture (IJV) literature (Berdrow \& Lane, 2003; Inkpen \& Dinur, 1998; Lyles \& Salk, 1996). In line with the argument that an IJV provides a 'vehicle' for complimentary knowledge exchange (Kogut \& Zander, 1992), numerous studies have examined the transfer (i.e. acquisition) of knowledge in the IJV context (Dhanaraj et al., 2004; Lyles \& Salk, 1996; Park, 2011). However, much less studies have paid attention to new knowledge creation in IJVs (Beamish \& Berdrow, 2003; Berdrow \& Lane, 2003; Fang \& Zou, 2010) and fewer have made empirical investigation (Pak, Ra, \& Lee, 2015; Yao et al., 2013). This paucity of research is rather surprising given that an IJV often represents an effective conduit for joint learning in which IJV partners engage in cooperative and synergistic learning to develop IJVspecific knowledge that benefit both partners (Beamish \& Berdrow, 2003; Fang \& Zou, 2010; Kogut \& Zander, 1992).

Organizational knowledge creation theory has accentuated that interaction between organization members and favorable organizational contexts that facilitate such interaction are crucial for knowledge creation (Nonaka \& Konno, 1998; Nonaka, Von Krogh, \& Voelpel, 2006). The interaction between organization members is often represented by the intensity of communication that refers to 'the information exchanged between partners in a relationship' (Costa e Silva, Bradley, \& Sousa, 2012:295). Communication renders a primary mechanism to acquire crucial information from others, enhance trust among counterparts (Kwon, 2008), and eventually facilitate interactions within the organization (Boersma, Buckley, \& Ghauri, 2003; Reus \& Lamont, 2009). Therefore, the importance of effective communication between partners in the context of inter-organizational collaboration such as IJVs cannot be overstated. Literature has revealed that communication is not only an essential means to achieve the benefits of the relationship (Cummings, 1984) but also a primary indicant of the partnerships' vitality (Mohr \& Spekman, 1994). It also presents an integral path to access partner's knowledge (Argote, 1999), capture the utility of the information exchanged (Mohr \& Spekman, 1994), and facilitate joint learning (Berdrow \& Lane, 2003).

However, we have little knowledge about how communication between partners affect new knowledge creation in IJVs. Given that one of the key motivations of creating an IJV is to achieve collaborative learning opportunities for value creation with partners contributing complementary knowledge and resources (Berdrow \& Lane, 2003; Inkpen \& Dinur, 1998; Kogut \& Zander, 1992), such lack of knowledge constitutes a major deficit in our understanding of IJV knowledge management. In particular, what has been remained underexplored is the distinctive role of formal and informal communication in IJV knowledge creation. Whereas it has been 
widely recognized that formal and informal communication have dissimilar roles in facilitating interaction and knowledge exchange (Daft \& Lengel, 1986; Gupta \& Govindarajan, 2000), we still do not know much about their different effects on knowledge creation in IJVs. Another deficit in current literature is that, despite the ample recognition of the importance of communication in the IJV context, the influence of organizational context on communication between IJV partners has been substantially underexplored. Communication within the organization requires appropriate or supporting organizational context (Inkpen, 1998; Nonaka \& Konno, 1998). Especially the role of organizational context on communication seems to be greater in IJVs than other forms of MNEs given that an IJV is an affiliation of two (or more) different organizational entities whose organizational and contextual dissimilarities often largely hamper effective communication between partners (Chen, Park, \& Newburry, 2009; Evangelista \& Hau, 2009; Lyles \& Salk, 1996).

This study aims to fill these research gaps by examining how organizational contexts, which we call 'organizational learning platform', influence formal and informal communications between IJV partners, and how two different types of communications affects new knowledge creation in IJVs.

\section{THEORETICAL BACKGROUND}

\section{Organizational Learning Platform}

The interaction between organization members is the prime source of organizational knowledge creation, while a favorable organizational environment amplifies such interaction and eventually facilitate knowledge creation (Nonaka \& Konno, 1998). This organizational environment has been referred as a 'shared space' for the resource concentration of organization knowledge that can be generated by coordinated organizational efforts (Nonaka \& Konno, 1998; Nonaka et al., 2006).

In the IJV context, a variety of barriers such as organizational differences and cultural misunderstanding can seriously impede the flow of information between IJV partners (Demirbag \& Mirza, 2000; Parkhe, 1993). Thus, developing an organizational infrastructure and effective communication channels has been regarded as a prerequisite condition for IJVs not only to facilitate flows of information but also to integrate the partners' knowledge (Lyles \& Salk, 1996). Accordingly, IJV partners need to establish an appropriate environment in which organization members can effectively interact with each other. We call this surrounding environment an 'organizational learning platform' defined as 'an organizational context that facilitates interaction among organization members for learning and new knowledge creation'.

Organizational learning platform is therefore a broad concept that involves a variety of organizational components that have been examined in prior literature. For example, organizational infrastructure such as system, rules, routines, and process (Barrick \& Mount, 1993; Fey et al., 2009) constitutes an important element. The institutional factors such as contract (Luo, 2002; Luo \& Park, 2004), the social capital aspects such as trust and commitment (Kwon, 2008; Li, 2005; Madhok, 2006), and the characteristics of IJV partners as well as their relationships also function as critical components of IJV organizational learning platform (Lyles \& Salk, 1996). National and organizational cultural differences can be another important element as they are closely associated with the conflicts between IJV partners, and further with integration issues in IJVs (Pak, Ra, \& Park, 2009). 
In this study, we focus on three elements of organizational learning platform, namely, commitment, cultural difference, and cultural alignment, that play a crucial role in communication between IJV partners.

\section{Formal and Informal Communication}

Communication can be defined as 'formal and informal sharing of meaningful and timely information between firms' (Anderson \& Narus, 1990:44). The exchange of information via formal and informal communications in organizational contexts is largely based on the concept of 'social network' introduced by Chandler (1962). In his seminal work, formal social networks refer to the 'management-generated structure' which usually prescribed according to the corporate strategy, while informal social networks are recognized as 'unsanctioned organic structures' which possibly link unbounded group of individuals (Mintzberg, 1979). In line with this, prior literature has revealed that the patterns of collaboration and communication in informal network are significantly different from those of formal network (Cross et al., 2001; Cross \& Parker, 2004), and that formal and informal communications play different roles in the exchange of information and knowledge (Gupta \& Govindarajan, 2000; Weedman, 1992).

Formal communication represents the interaction based on the regulative institutional factors such as policies and rules. Thus it is typically conducted through regular meetings, official seminars, conferences, and discussions (Davis, 1953). Employing liaison person, task forces, and permanent committees also encourage formal communication within or between organizations (Galbraith, 1973; Nadler \& Tushman, 1988). On the other hand, informal communication represents the interaction based on personal network and community (Knippen, 1974). Informal communication closely relates to the emotional or relational factors such as interpersonal familiarity, trust, and affinity (Edström \& Gaibraith, 1977; Van Maanen \& Schein, 1977) that help to increase openness of communication and sequentially elevate the richness of communication channels (Daft \& Lengel, 1986). Thus, formal and informal communications have different underlying mechanism, functions, and impacts (Burt, 1992).

Given such differences, organizational contexts may have different influences on formal and informal communication. For instance, IJV parent firms can achieve a certain degree of control in enhancing formal communication between partners that usually takes place in management-generated structure based on regulative policies and rules prescribed. But it is more difficult for them to enhance informal communication between IJV members which basically relies on the personal relationship on which firms have much less control (Burt, 1992; Chandler, 1962; Su et al., 2009).

\section{HYPOTHESIS DEVELOPMENT}

\section{Commitment between IJV Partners and Communication}

Organization studies have identified two types of commitments relevant to international cooperative relationships: behavior commitment and attitudinal commitment (Reichers, 1985). While behavioral commitment focuses on the behaviors of continuing the relationship and compliance to organizational rules (Becker, 1960; Coleman, 1990; Morris \& Sherman, 1981), attitudinal commitment highlights the acceptance of organizational goals and values, and a willingness to make efforts for the organization (Mowday, Porter, \& Steers, 1982). In other words, behavioral commitment represents the instrumental side of the relationships, while 
attitudinal commitment depicts the affective elements (Cullen, Johnson, \& Sakano, 1995).

Therefore, commitment provides an integral ground for both formal and informal communications. Commitment is positively related to the mutual dependence in organizational relationship (Chetty \& Eriksson, 2002; Holm, Eriksson, \& Johanson, 1999) which refers to the needs of firms to maintain an exchange relationship with their partners (Frazier, 1983). An IJV is a valuable conduit for each partner to exchange complementary assets, and thereby, IJVs with higher commitment will have more intense communication with partners in order to maintain their valuable relationship and access to complementary knowledge (Mohr \& Spekman, 1994). Given that commitment involve both instrumental and affective elements, we hypothesize that commitment between IJV partners will have positive relationship with both formal and informal communication, such that behavioral commitment positively affects formal communication, while attitudinal commitment positively influences informal communication $(H 1 a \& H 1 b)$.

However, behavioral commitment between partners can be, to some extent, guaranteed as the formation of IJV relationship is based on the contract and engagement. But attitudinal commitment or voluntary commitment based on interpersonal relationship and embeddedness is more difficult to guarantee with the formation of relationship, but is more likely to be contingent on relationship evolvement (Madhok, 2006; Su et al., 2009; Uzzi, 1996). Therefore, the impact of commitment will be stronger on formal communication than informal communication (H1c).

\section{Cultural Distance in IJVs and Communication}

Cultural distance can influence all distinguished group (Hofstede, 2001). Particularly, in IJV context, cultural difference can be perceived in multiple levels (Sirmon \& Lane, 2004) such as national, organizational, and working-group level (Pothukuchi et al., 2002). The influence of cultural distance on communication between IJV partners is not conclusive. Culture underlies human communication since people use idiosyncratic languages such as words, idioms, and expressions that are unique within their culture (Zeybek et al., 2003). Thus cross-cultural communication often accompanies frequent misunderstanding (Si \& Bruton, 1999). Distinctive communication style and expectation embedded in different cultures also impede knowledge sharing (Lane, Greenberg, \& Berdrow, 2004; Reus \& Lamont, 2009). Therefore, cultural distance between IJV partners is generally deemed to be detrimental to the communication between them. Paradoxically, however, cultural distance may encourage communication between IJV partners as it may increase learning opportunities between the partners (Barkema \& Vermeulen, 1998; Cox, 1991; Reus \& Lamont, 2009). Diversity embedded in different culture provides IJV partners great opportunities of learning and knowledge creation (Morosini, Shane, \& Singh, 1998), and thereby, cultural distance may increase the "combination potential" of IJVs (Larsson \& Finkelstein, 1999), encouraging communication between partners.

Nonetheless cultural difference has both positive and negative influences on the communication, IJV partners will exert for the benefits of cultural difference while minimizing its drawbacks. However, their efforts may not bring the same result from formal and informal communications. While they can exercise a certain degree of control over formal communication through regulations or policies (Burt, 1992), they generally face more difficulties in facilitating informal communication that is a sort of spontaneous activity and often promoted by interpersonal relationship, personal familiarity, and affinity on which organizations have less control (Burt, 1992; Su et al., 2009). Thus in the context of high cultural differences, IJV partners may promote the formal communication to prevent or offset the possible negative influence as 
well as to benefit from cultural diversity, but it will be much difficult to promote informal communication as it is based on the personal relationships and affinities between IJV members. Thus cultural differences between IJV partners will lead to a positive degree of formal communication between IJV partners $(H 2 a)$, but a negative degree of informal communication. between IJV partners $(H 2 b)$.

\section{Cultural Alignment in IJVs and Communication}

Cultural alignment that reduces various cultural and psychological gaps between IJV partners plays a significant role in facilitating integration as well as communication between partners (Inkpen, 1998). Cultural alignment is highly associated with having a 'shared mindset' related to IJV-specific values, goals, and missions (Buckley, Clegg, \& Tan, 2006; Costa e Silva et al., 2012; Li, 2005), which provides IJV members a foundation of strong 'social bonds' (Dhanaraj et al., 2004; Dyer \& Nobeoka, 2000) and 'common fate' (Zaheer, McEvily, \& Perrone, 1998) that alleviate 'we versus them' attitude towards IJV partners (i.e. social categorization) (Hofstede, 1984; Tajfel, 1978). Moreover, cultural alignment helps IJVs to develop a relational embeddedness that largely facilitates information exchange between IJV partners (Dhanaraj et al., 2004), while providing a favorable condition for collaboration in an inter-firm relationship (Dyer \& Singh, 1998).

However, realizing cultural alignment is never uncomplicated, particularly in IJVs that typically have two different firms with partial ownerships. With regard to this, a contractual mechanism may provide IJVs with an effective means to achieve cultural alignment. IJV contracts provide a legally bound institutional framework that guides the facilitation of information exchange and the prevention of opportunism (Hagedoorn \& Hesen, 2007b; Luo, 2002). Contracts provide IJVs the rights and warranties to execute some degree of control over clauses, rules, plans, and procedures included in their agreement (Yan, Chong, \& Mak, 2010). Therefore, adopting a contractual mechanism which includes plans to enhance social bonds and reduce cultural gaps can help IJV partners to achieve cultural alignment which will lead to meaningful communication and knowledge exchange between partners.

Therefore, cultural alignment will support IJVs to create a 'single social community' which in turn facilitates both formal and informal communications between IJV partners $(H 3 a \&$ $H 3 b)$. However, the influence of cultural alignment will be greater on informal communication rather than on formal communication because sharing a common culture or mindsets is mainly related to emotional or relational factors such as interpersonal bonds and familiarity that are closely associated with informal communication (Su et al., 2009) (H3c).

\section{Communication and Knowledge Creation}

The exchange of complementary knowledge possessed by IJV partners is a key success factor for new IJV knowledge creation (Berdrow \& Lane, 2003; Fang \& Zou, 2010; Inkpen \& Dinur, 1998). A relevant modification of transferred knowledge (Pak et al., 2015) and adequate absorptive capacity (Cohen \& Levinthal, 1990) are also known to be essential for knowledge creation in the IJV context. Effective communication enables IJV members to gain access to complementary knowledge from partners, exchange requisite information, and thereby, achieve inter-organizational or joint learning (Lane, Salk, \& Lyles, 2001; Si \& Bruton, 1999; Simonin, 2004). Therefore, communication between IJV partners functions as an essential determinant of 
knowledge creation in IJVs, but we believe that the influence of formal and informal communications on IJV knowledge creation will not be identical since they have different functions and mechanisms.

Formal communication is particularly significant in procuring timely information, creating mutual support and volitional compliance (Mohr \& Nevin, 1990). Most often times, IJV members can acquire necessary information and complementary knowledge from partners through formal communication such as official meeting and regular discussion, which become a foundation of new knowledge creation. Formal communication is typically based on the regulative institutional factors, and thus it functions as an assured direct channel to IJV partners, providing a certain level of communication quality in terms of accuracy, adequacy, timeliness, and credibility of knowledge exchanged (Daft \& Lengel, 1986; Huber \& Daft, 1987), compared to informal communication. On the other hand, informal communication can provide IJV members a unique sort of communication effectiveness which is difficult to replicate through formal communication (Mohr \& Nevin, 1990; Su et al., 2009; Uzzi, 1996). Moreover, as informal communication is particularly powerful in interacting through the personal network and community (Knippen, 1974), it can expand the range of knowledge exchanged and provide possibilities to achieve richer and more reliable information which could not be acquired via formal communication (Uzzi, 1996).

In sum, we postulate that both formal and informal communications will make respective and complementary contributions to new IJV knowledge creation (H4a \& H4b).

\section{METHOD AND RESULTS}

The empirical analysis of this study was conducted by structural equation modeling using survey data collected from 136 Korean parent firms of IJVs. To avoid non-response bias two standard surveys were conducted at two different times. The questionnaire was designed very carefully to minimize possible common method bias, and Harman's one-factor test was fulfilled. The measurement of the variables was mostly derived from relevant prior studies. The result supported H1a, H1c, H2a, H3a, H3b, H3c, H4a, H4b, while rejecting H1b and H2b.

\section{CONCLUSION}

This study seeks three contributions. First, this study extends our understanding of IJV knowledge creation by investigating the mediating role of formal and informal communications between organizational contexts and knowledge creation. Second, this study deepens our understanding of the role of communication in the IJV context by demonstrating the differentiated role of formal and informal communications on IJV knowledge creation. Finally, this study provides several insights to the practitioners, especially to the managers of parent firms that create IJVs for joint learning and new knowledge creation. Particularly given that in recent years the motivation for creating IJVs has shifted from exploitation of natural resources to exploration of new knowledge (Beamish \& Berdrow, 2003), the findings of this investigation on the path of IJV knowledge creation provide some useful implications.

\section{"REFERENCES AVAILABLE FROM THE AUTHOR(S)"}

